\title{
O PROCESSO DE
}
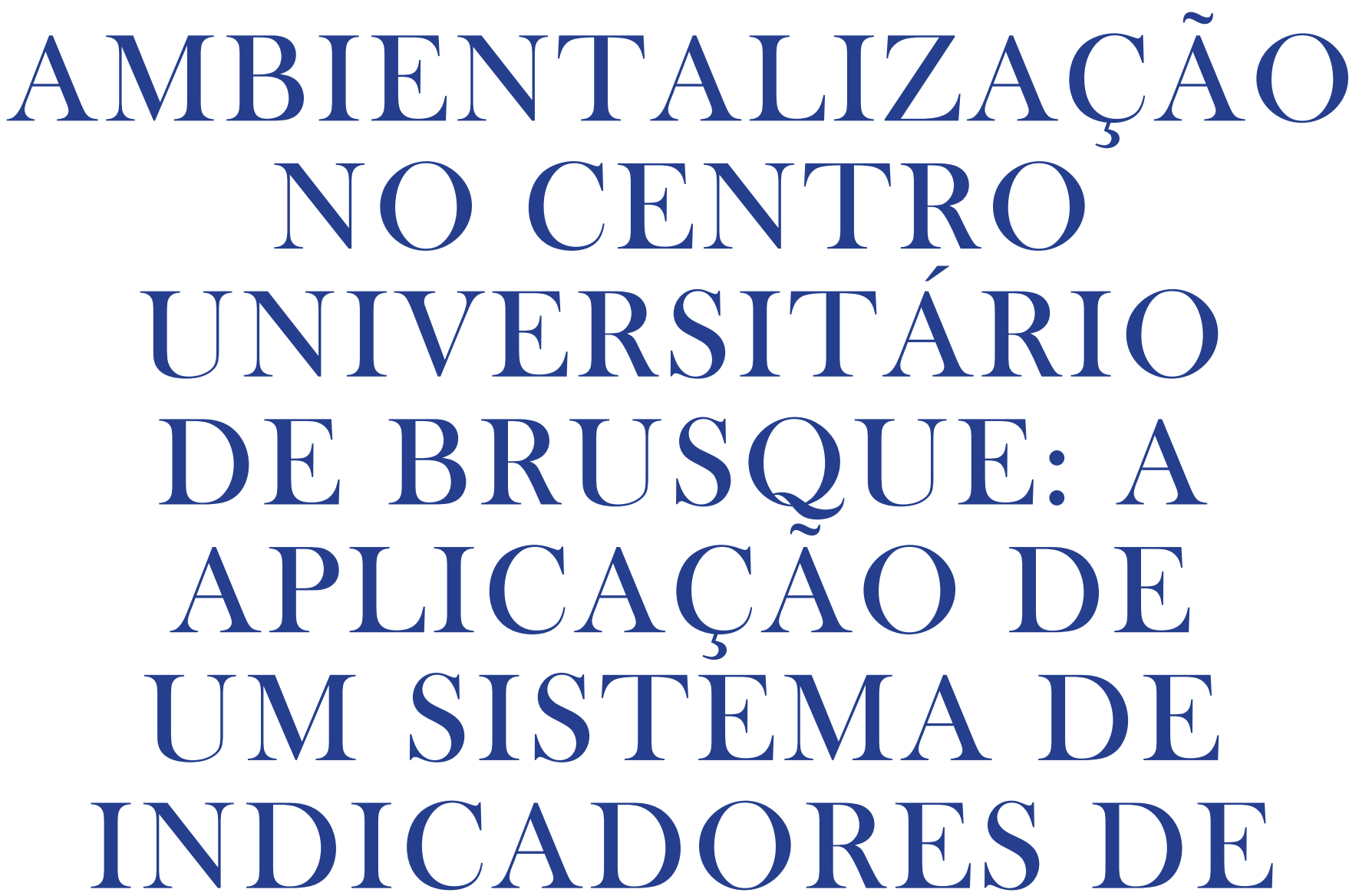

SUSTENTABILIDADE

THE PROCESS OF GREENING AT THE CENTRO UNIVERSITÁRIO DE BRUSQUE: THE APPLICATION OF A SYSTEM OF SUSTAINABILITY INDICATORS

EL PROCESO DE AMBIENTALIZACIÓN EN EL CENTRO UNIVERSITARIO DE BRUSQUE: LA APLICACIÓN DE UN SISTEMA DE INDICADORES DE SUSTENTABILIDAD

Mara Lúcia Figueiredo Doutora em Zootecnia pela UNESP. Assessora em Sustentabilidade e Docente da UNIFEBE.

Márcia Maria Junkes

Doutoranda em Educação pela UADE. 
Heloisa Maria Wichern Zunino

Mestre em Educação pela UNIVALI.

George Wilson Aiub

Mestre em Engenharia de Produção pela UFSC.

Eliane Renata Steuck

Mestranda em Educação pela UNIVALI.

Assessoria de Sustentabilidade Centro Universitário de Brusque (UNIFEBE)

Brusque - SC - Brasil

Endereço:

Rua Dorval Luz, 123

Santa Terezinha - Brusque - SC

CEP: $88352-400$

E-mails:

maraluciafg@unifebe.edu.br mmjunkes@unifebe.edu.br helo@unifebe.edu.br georgeaiub@unifebe.edu.br liasteuck@gmail.com

Resumo: Objetivando contribuir com os processos de ambientalização nas Instituições de Educação Superior (IES), este artigo apresenta uma das etapas deste processo no Centro Universitário de Brusque - UNIFEBE: a aplicação de um sistema de indicadores de sustentabilidade, proporcionada pela participação no projeto Definición de indicadores de evaluación de la sustentabilidad en Universidades Latinoamericanas, um projeto da Red de Indicadores de Sostenibilidad Universitaria (RISU). Referido projeto tinha por objetivo principal a aplicação 
de um sistema de indicadores que permitisse avaliar os compromissos com as dimensões da sustentabilidade nas universidades, propiciando a reflexão sobre suas fragilidades ou potencialidades na inserção desta temática. Na UNIFEBE, a pesquisa caracterizou-se pelo enfoque quanti-qualitativo com a realização de entrevistas, aplicando um questionário composto por 114 indicadores de sustentabilidade. O processo desencadeado pela realização desta investigação e seus resultados permitiram identificar indícios da incorporação das dimensões da sustentabilidade na gestão, no ensino, na pesquisa e na extensão, bem como as fragilidades, as dificuldades e os desafios frente à necessidade desta inserção. Ele também impulsionou alguns avanços no processo de ambientalização, tais como: ampliação da discussão dessa temática na IES, com o fortalecimento da parceria, da integração e da colaboração entre gestores, docentes, colaboradores e acadêmicos em prol da construção da Política de Ambientalização e a aprovação de seu Regulamento. Consideramos o sistema de indicadores proposto pelo projeto da RISU uma ferramenta imprescindível na construção de Políticas Institucionais de Ambientalização e Sustentabilidade nas IES.

Palavras-chave: Indicadores de sustentabilidade. Políticas Institucionais de Ambientalização. Educação Superior. Espaços educadores sustentáveis.

Abstract: With the objective of contributing to the processes of greening in Higher Education Institutions (HEI), this article presents one of the stages in this process at the Centro Universitário de Brusque - UNIFEBE: the application of a system of sustainability indicators, made possible by the participation in the project Definition of indicators for evaluating sustainability in Latin American Universities, which is part of the Network of Sustainability Indicators in Universities (RISU) project. The main aim of the project was to apply a system of indicators to enable the evaluation of commitments to the dimensions of sustainability in universities, offering a reflection about its fragilities or 
potentials related to the insertion of this theme. At UNIFEBE, the research was characterized by a quantitative and qualitative focus, with the application of interviews, using a questionnaire composed of 114 sustainability indicators. The resulting process of this investigation, and its results, enabled the identification of indices on the incorporation of the dimensions of sustainability in the administration, teaching, research and extension activities, as well as the fragilities, difficulties and challenges posed by this insertion. It also led to some advances in the process of greening, such as: broadening the discussion of this theme in HEIs, strengthening the partnership, and promoting integration and collaboration among administrators, teachers, employees and students, for the construction of a Policy of Greening and the approval of is Regulation. We consider the system of indicators proposed by the RISU project to be an essential tool in the construction of the Institutional Policies on Greening and Sustainability in HEIs.

Keywords: Sustainability Indicators. Institutional Policies of Greening. Higher Education. Sustainable Educational Spaces.

Resumen: Con el objetivo de contribuir con los procesos de ambientalización en las Instituciones de Educación Superior (IES), este artículo presenta una de las etapas de este proceso en el Centro Universitario de Brusque - UNIFEBE: la aplicación de un sistema de indicadores de sostenibilidad, proporcionada por la participación en el proyecto Definición de indicadores de evaluación de la sostenibilidaden Universidades Latinoamericanas, un proyecto de la Red de Indicadores de Sostenibilidad Universitaria (RISU). El mencionado proyecto tiene como objetivo principal la aplicación de un sistema de indicadores que permita evaluar los compromisos con las dimensiones de la sostenibilidad en las universidades, propiciando la reflexión sobre sus fragilidades o potencialidades en la inserción de esta temática. En la UNIFEBE la investigación se caracterizó por el enfoque cuantitativo y cualitativo, con la realización de entrevistas, aplicando un cuestionario compuesto por 114 indicadores de 
sostenibilidad. El proceso desencadenado con la realización de esta investigación y sus resultados permitió identificar indicios de incorporación de las dimensiones de la sostenibilidad en la gestión, en la enseñanza, en la investigación y en la extensión, así como las fragilidades, dificultades y desafíos frente a la necesidad de esta inserción. Impulsó también algunos avances en el proceso de ambientalización, tales como: ampliación de la discusión de esta temática en la IES con el fortalecimiento de la integración y la colaboración entre administradores, docentes, colaboradores y alumnos en pro de la construcción de la Política de Ambientalización y la aprobación de su Reglamento. Consideramos el sistema de indicadores propuesto por el proyecto de la RISU una herramienta imprescindible en la construcción de Políticas Institucionales de Ambientalización y Sostenibilidad en las IES.

Palabras clave: Indicadores de sostenibilidad. Políticas Institucionales de Ambientalización. Educación Superior. Espacios educadores sostenibles.

\section{AMBIENTALIZAÇÃO NA EDUCAÇÃO SUPERIOR}

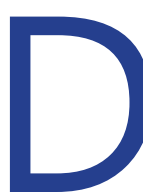

e acordo com Junyent, Geli e Arbat (2003),

(...) la Ambientalización Curricular es un proceso continuo de producción cultural tendiente a la formación de profesionales comprometidos con la búsqueda permanente de las mejores relaciones posibles entre la sociedad y la naturaleza, atendiendo a los valores de la justicia, la solidaridad y la equidad, aplicando los principios éticos universalmente reconocidos y el respeto a las diversidades. (JUNYENT; GELI; ARBAT, 2003, p. 21).

Para Kitzmann(2007, p. 554), "ambientalizaro ensino significa inserir a dimensão socioambiental onde ela não existe ou está tratada de forma inadequada".

Portanto, esta inserção requer educar para a sustentabilidade socioambiental, com a inclusão e a integração de conhecimentos, critérios e valores (sociais, éticos, estéticos e ambientais) em diferentes níveis e espaços educativos (GUERRA; FIGUEIREDO, 2014).

Nesse contexto, as Instituições de Educação Superior (IES), como promotoras e responsáveis pelo processo de construção do conhecimento e das formadoras de valores, assumem um papel fundamental frente à ambientalização e ao 
enraizamento da Educação Ambiental "em todos os níveis de ensino", como determinam a Política Nacional (BRASIL, 1999), o Programa Nacional de Educação Ambiental - ProNEA (BRASIL, 2005) e a Resolução n² 2, de 15 de junho de 2012, que estabelece as Diretrizes Curriculares Nacionais para a Educação Ambiental DCNEA (BRASIL, 2012).

Mencionada responsabilidade requer das universidades comprometerse com o processo de ambientalização, uma vez que ele exige uma série de transformações em que, de acordo com Leff (2004, p.217), a incorporação do saber ambiental nas IES e na formação profissional requer "a abertura de paradigmas teóricos, das barreiras institucionais e dos interesses disciplinares", bem como "a elaboração de novos conteúdos curriculares de cursos, carreiras e especialidades.". Para este autor,

(...) a ambientalização da educação é um processo mais complexo do que a ensamblagem de disciplinas dispersas, que sua integração sistêmica e a colaboração de especialistas provenientes de diversos campos do conhecimento para tratar (pesquisar, ensinar) um problema em comum. (LEFF, 2004, p. 217).

Nesse sentido, promover a ambientalização curricular no processo educacional significa instaurar, no sistema educativo, uma série de mudanças que incluam:

[...] innovaciones conceptuales, metodológicas y actitudinales, pero también estructurales y organizativas; que permita los enfoques interdisciplinares; que facilite un planteamiento global de objetivos y contenidos; que acerque a la comprensión de la complejidad y a la visión planetaria. [...] que faciliten la descentralización y la flexibilidad del currículo necesaria para adaptarse al entorno y dar respuesta a sus inquietudes. (GONZÁLES MUÑOZ, 1996, p. 37-8).

Frente ao desafio e inspirados por Gonzáles Muñoz, os autores Kitzmann e Asmus (2012, p. 270) propõem "o conceito de ambientalização sistêmica", na tentativa de ressignificar conteúdos, metodologias, materiais, atividades e estruturas educativas e organizacionais, num processo que "extrapole a concepção estrita (stricto sensu) de currículo", inclua os "aspectos ambientais em todas as dimensões da organização e funcionamento da universidade" (OLIVEIRA; FREITAS, 2002, p. 156) e "articulem a ambientalização da estrutura curricular à ambientalização de todo o campus" (SANTANA; CAVALARI; CARVALHO, 2003, p. 134). Por seu caráter sistêmico, referida ambientalização prevê mudanças institucionais, como a adequação da infraestrutura e de normas de funcionamento (KITZMANN; ASMUS, 2012).

Assim, objetivando contribuir com os processos de ambientalização nas Instituições de Educação Superior (IES); este artigo apresenta uma das etapas 
deste processo no Centro Universitário de Brusque - UNIFEBE: a aplicação de um sistema de indicadores de sustentabilidade, proporcionada pela participação no projeto Definición de indicadores de evaluación de la sustentabilidad en Universidades Latinoamericanas, um projeto da Red de Indicadores de Sostenibilidad Universitaria (RISU).

\section{A UNIFEBE E O PROJETO DA RISU}

Ao longo dos últimos anos, a UNIFEBE vem se destacando no campo socioambiental e da responsabilidade social por prêmios recebidos (Selo Social), trabalhos, projetos e estudos que integram pesquisa, ensino e extensão, e pela realização de eventos, como o Encontro de Ensino Pesquisa e Extensão (ENPEX), o Fórum de Prevenção de Desastres Ambientais da Bacia Hidrográfica do Rio Itajaí, e o Congresso de Inovação, Tecnologia e Sustentabilidade.

Em 2012, por iniciativa da Reitoria da UNIFEBE, é criada a Assessoria de Sustentabilidade que, dentre suas ações, promove a aproximação desta IES às Redes de Educação Ambiental. Com isto, neste ano, a UNIFEBE torna-se instituição-elo da Rede Sul Brasileira de Educação Ambiental (REASul) e passa a integrar a Alianza de Redes Iberoamericanas por la Sustentabilidad y el Ambiente (ARIUSA), proporcionando a participação de pesquisadores, gestores e docentes da UNIFEBE nas Redes de Projetos da ARIUSA, tais como a: Red de Investigación sobre Ciencia, Tecnología, Innovación y Educación Ambiental en Iberoamérica (CTIE-AMB); Red de la Revista Iberoamericana Universitaria en Ambiente, Sociedad y Sostenibilidad (AMBIENS) e Red de Indicadores de Sostenibilidad en las Universidades (RISU).

Em 2013, constitui-se o Comitê de Sustentabilidade, com o objetivo de executar ações no âmbito da formação acadêmica para ambientalização; agregar atividades de currículo, pesquisa, iniciação científica, extensão e gestão voltadas às questões da sustentabilidade e da responsabilidade socioambiental; e integrar gestores, pesquisadores, docentes e acadêmicos em torno da criação de uma Política Institucional de Ambientalização.

Como mencionado, a criação de uma Política Institucional, construída em um amplo processo de ambientalização, exige uma série de transformações nas IES. Este processo, dentre uma série de outras demandas, requer que sejam 
estabelecidas metodologias e estratégias que permitam não só identificar indícios da incorporação das diferentes dimensões da sustentabilidade em todos os contextos e espaços das comunidades universitárias, como também avaliar a construção e/ou a implementação das Políticas de Ambientalização e de Responsabilidade Social nas universidades.

A preocupação em estabelecer critérios que permitam avaliar as IES frente à inserção da temática socioambiental tem motivado a produção de estatísticas, indicadores e índices. De acordo com Carvalho e Barcellos (2009),

Os indicadores ambientais começaram a ser desenvolvidos por vários países europeus, pelo Canadá e pela Nova Zelândia nos anos 80. O grande marco, no entanto, foi a assinatura pelos representantes de 179 países da Agenda 21, um dos principais documentos da segunda Conferência da ONU Sobre Meio Ambiente e Desenvolvimento, realizada no Rio de Janeiro, em 1992. Nesse documento, no capítulo 40, afirma-se a necessidade de se desenvolverem indicadores de desenvolvimento sustentável (DS) por parte dos países signatários. (CARVALHO; BARCELLOS, 2009, p. 2).

Entretanto, definir indicadores de sustentabilidade requer que se considerem suas diferentes dimensões: ambientais (ecológicas), econômicas, sociais, culturais, éticas, epistemológicas, dentre outras. Isto exige que sejam definidos parâmetros, indicadores e padrões que permitam mensurar, monitorar e avaliar a incorporação das dimensões da sustentabilidade em todos os contextos e espaços das comunidades universitárias. Mas como mensurar, avaliar e medir a sustentabilidade? Que ações, observadas nas IES, indicam sua incorporação?

Frente a essa necessidade, importantes pesquisas no Brasil (GUERRA; FIGUEIREDO, 2014; GUERRA; FIGUEIREDO; RUSCHEINSKY, 2014; FIGUEIREDO; GUERRA, 2014; RUSCHEINSKY et al., 2014; KITZMANN; ASMUS, 2012; LEME et al., 2012; GUERRA; FIGUEIREDO; SAENZ, 2012; KITZMANN, 2007) e na Espanha (BARRON; NAVARRETE; DIDAC, 2010) vêm discutindo essa temática e buscando por estratégias e indicadores que permitam avaliar o processo de ambientalização nas IES. A maioria dos trabalhos realizados na Espanha provém de um Grupo de Trabalho proposto pela Conferencia de Rectores para las Universidades Españolas (CRUE), do qual participa a Universidad Autónoma de Madrid (UAM).

Comprometidos com essa busca, pesquisadores procedentes de 14 países (Argentina, Brasil, Chile, Colômbia, Costa Rica, Cuba, Espanha, Guatemala, Quênia, México, Panamá, Peru, República Dominicana e Venezuela) reuniram-se, em dezembro de 2013, em Viña del Mar, no Chile, e desta parceria nasceu o projeto Definición de indicadores de evaluación de la sustentabilidad en Universidades 
Latinoamericanas, impulsado pelo Instituto de Investigación Avanzada sobre Evaluación de la Ciencia y la Universidad (INAECU) em colaboração com a Red de Indicadores de Sostenibilidad Universitaria (RISU) de ARIUSA, com o apoio financeiro do Centro de Estudios de América Latina de la Universidad Autónoma de Madrid (UAM) e do Banco Santander.

Referido projeto tinha por objetivos principais:

Fortalecer el trabajo conjunto y las acciones en red que vienen desarrollando las universidades de la región preocupadas por la sostenibilidad y la responsabilidad social; Definir un marco de análisis para la evaluación de las políticas de sostenibilidad y responsabilidad social en las universidades latinoamericanas; Formar a responsables universitarios en la aplicación de sistemas de indicadores para evaluar los compromisos con la sostenibilidad de sus universidades; Reflexionar sobre las deficiencias o puntos fuertes de la aplicación de sistemas de indicadores en las universidades latinoamericanas, diseñados dentro de procesos internos de autoevaluación; Potenciar la sostenibilidad y la responsabilidad social en las universidades latinoamericanas por medio de una propuesta de estrategia regional de acciones de mejora. (BENAYAS, 2014, p. 15).

Para alcançar estes objetivos, uma sequência de ações foi desencadeada, culminando num conjunto de 114 indicadores, estruturados em três grandes setores: organização, docência e pesquisa, e gestão ambiental na universidade. Estes indicadores constituem 11 dimensões da sustentabilidade relacionadas com os campos da política institucional; sensibilização e participação da comunidade universitária; responsabilidade socioambiental; docência; pesquisa, extensão, transferência de tecnologia; urbanismo e biodiversidade; energia; água; mobilidade; resíduos; e contratação responsável (licitações sustentáveis ou "compras verdes").

Sessenta e cinco universidades de 10 países latino-americanos (Argentina, Brasil, Colômbia, Costa Rica, Chile, Guatemala, México, Peru, República Dominicana e Venezuela) finalizaram a aplicação dos indicadores. Destas, 13 são brasileiras: quatro de Santa Catarina (Centro Universitário de Brusque - UNIFEBE, Universidade do Vale do Itajaí - UNIVALI, Universidade da Região de Joinville UNIVILLE e Universidade do Estado de Santa Catarina - UDESC), uma do Paraná (Universidade Estadual do Oeste do Paraná - UNIOESTE), cinco do Rio Grande do Sul (Universidade Federal do Rio Grande - FURG, Universidade do Vale do Rio dos Sinos - UNISINOS, Pontifícia Universidade Católica do Rio Grande do Sul PUC-RS, Universidade de Passo Fundo - UPF e Universidade Regional Integrada do Alto Uruguai e das Missões - URI) e três de São Paulo (Universidade de São Paulo - USP, Universidade Metodista de Piracicaba - UNIMEP e Universidade Federal de São Carlos - UFSCar). 
Se se considerar o universo de 2391 Instituições de Educação Superior no Brasil (BRASIL, MEC/INEP, 2013), a amostra brasileira (13 IES) pode ser considerada insignificante $(0,54 \%)$. No entanto, ao se constar que dentre as 13 IES participantes do projeto, 12 são universidades e que, de acordo com o Censo da Educação Superior (BRASIL, MEC/INEP, 2013), o Brasil tem um total de 195 instituições consideradas como universidades, a amostra brasileira passa a ser $6,15 \%$, semelhante, portanto, ao índice amostral (6\%) do projeto realizado em 65 universidades de 10 países latino-americanos (BENAYAS, 2014).

Na UNIFEBE, único Centro Universitário participante do projeto, pesquisadores preocupados com integração de gestores, pesquisadores, docentes e acadêmicos em torno da criação de uma Política Institucional de Ambientalização acreditaram nos Indicadores de Sustentabilidade como instrumento na ampliação da discussão da temática da ambientalização nesta instituição, bem como ferramenta imprescindível na identificação de indícios das diferentes dimensões da sustentabilidade na gestão, no ensino, na pesquisa e na extensão.

\section{O PROCESSO DE AMBIENTALIZAÇÃO E A APLICAÇÃO DOS INDICADORES DE SUSTENTABILIDADE NA UNIFEBE}

Desde a criação da Assessoria de Sustentabilidade, em 2012 e, principalmente, com a institucionalização do Comitê de Sustentabilidade, em 2013, gestores, pesquisadores e docentes da UNIFEBE vêm empreendendo esforços na busca de subsídios à elaboração de uma Política Institucional de Ambientalização no âmbito desta IES.

Nessa expectativa, com o objetivo de identificar indícios de ambientalização nos planos de ensino dos Cursos de Graduação, foram analisados, por meio do uso de técnicas de análise documental e de Análise de Conteúdo (BARDIN, 2008), 450 planos de ensino de 379 disciplinas, ofertadas no primeiro semestre de 2013 em 15 cursos de graduação. Os resultados desta análise mostraram que conteúdos pertinentes à "sociedade" estão fortemente presentes na maioria das disciplinas de todos os cursos. No entanto, temas como "ecologia", "sustentabilidade" e "natureza" são pouco abordados (FIGUEIREDO; GUERRA, 2014).

No entanto, a análise documental nos planos de ensino indicava apenas o início de uma longa caminhada. Fazia-se necessário um instrumento que 
permitisse identificar iniciativas, abordagens e metodologias relacionadas com as diferentes dimensões da sustentabilidade não somente no ensino, mas também nos demais setores, como na gestão, na pesquisa e na extensão.

Assim, na UNIFEBE, a pesquisa com os Indicadores de Sustentabilidade, do projeto da RISU, caracterizou-se pelo enfoque quanti-qualitativo, com a realização de entrevistas, aplicando um questionário composto por 114 indicadores de sustentabilidade. Para tal, foram identificados atores cuja prática, conhecimento e histórico na IES permitisse responder fidedignamente às questões colocadas. Com isto, foram contatados e entrevistados o Reitor, os Pró-Reitores de Administração (PROAD), de Ensino de Graduação (PROENG), e de Pós-Graduação, Pesquisa e Extensão (PROPPEX). Também colaboraram com a pesquisa os responsáveis pela Assessoria Jurídica e de Comunicação.

O processo desencadeado pela realização desta investigação e os seus resultados permitiram identificar indícios da incorporação das dimensões da sustentabilidade, ainda que pontuais, nos diversos setores da UNIFEBE, bem como apontar as fragilidades, as dificuldades e os desafios frente à necessidade desta inserção. Ele também impulsionou alguns avanços no processo de ambientalização, tais como: ampliação da discussão desta temática na IES; fortalecimento da parceria, integração e colaboração entre gestores, docentes, colaboradores e acadêmicos em prol da construção da Política de Ambientalização; aprovação do Regulamento da referida Política; e desencadeou o processo de elaboração da Política de Acessibilidade e Inclusão.

O Quadro 1 explicita a análise desses resultados, bem como apresenta avanços e desafios, que são discutidos em seguida. 
Quadro 01 - Avanços e desafios na UNIFEBE identificados pela pesquisa com os indicadores do projeto da RISU

\begin{tabular}{|c|c|c|}
\hline Dimensão & Avanços & Desafios \\
\hline Política Institucional & $\begin{array}{l}\text { Aprovação do Regulamento da Política } \\
\text { de Ambientalização. } \\
\text { Inclusão da Política de Ambientalização } \\
\text { da UNIFEBE no Plano de } \\
\text { Desenvolvimento Institucional (PDI). } \\
\text { Ampliação da carga horária (ainda que } \\
\text { parcial) de um profissional atuando na } \\
\text { área de sustentabilidade/meio ambiente. } \\
\text { Fortalecimento do envolvimento } \\
\text { de docentes, alunos e técnicos- } \\
\text { administrativos no processo de } \\
\text { ambientalização, pela institucionalização } \\
\text { do Comitê de Sustentabilidade e criação } \\
\text { de um Grupo de pesquisa (Grupo de } \\
\text { Pesquisa Educação, Meio Ambiente e } \\
\text { Sociedade -GEMAS), cadastrado no } \\
\text { Diretório de Grupos do CNPq. }\end{array}$ & $\begin{array}{l}\text { Estruturar um escritório ou } \\
\text { serviço de sustentabilidade } \\
\text { para implantar um sistema } \\
\text { de avaliação de impacto } \\
\text { ambiental e obter recursos } \\
\text { para desenvolvimento de } \\
\text { ações na área. } \\
\text { Recursos e autonomia para } \\
\text { investimentos e atividades } \\
\text { na área. }\end{array}$ \\
\hline $\begin{array}{l}\text { Sensibilização } \\
\text { e participação } \\
\text { da comunidade } \\
\text { Universitária. }\end{array}$ & $\begin{array}{l}\text { São realizadas algumas pesquisas } \\
\text { e atividades extracurriculares sobre } \\
\text { sustentabilidade. } \\
\text { Existem alguns cursos de extensão } \\
\text { universitária sobre a temática ambiental } \\
\text { ou de sustentabilidade. }\end{array}$ & $\begin{array}{l}\text { Um plano de ação } \\
\text { de formação para os } \\
\text { colaboradores técnicos e } \\
\text { administrativos. } \\
\text { Superação da ideia } \\
\text { de ações isoladas da } \\
\text { ação ambiental ou pela } \\
\text { sustentabilidade. }\end{array}$ \\
\hline $\begin{array}{l}\text { Responsabilidade } \\
\text { Socioambiental. }\end{array}$ & $\begin{array}{l}\text { Elaboração de documentos e memórias } \\
\text { dos investimentos na área. }\end{array}$ & $\begin{array}{l}\text { Ampliar o vínculo com a } \\
\text { comunidade empresarial, } \\
\text { ONGs e governamentais } \\
\text { sobre questões de } \\
\text { meio ambiente e } \\
\text { sustentabilidade. } \\
\text { Fortificar um plano de } \\
\text { comunicação das ações } \\
\text { realizadas na universidade. } \\
\text { Identificar e monitorar o } \\
\text { impacto ambiental gerado } \\
\text { pela instituição. } \\
\text { Criar um programa } \\
\text { de intervenção para a } \\
\text { resolução de problemas } \\
\text { relacionados à questão } \\
\text { socioambiental na } \\
\text { comunidade. }\end{array}$ \\
\hline
\end{tabular}


Realização de alguns trabalhos de conclusão de curso relacionados à temática da sustentabilidade.

Docência.

Análise documental nos Planos de ensino na busca pela incorporação socioambiental.
Desenvolver uma ferramenta para avaliar a incorporação de temática socioambiental nos cursos de graduação e pósgraduação;

Criação de comissão para assessorar as coordenações de curso na adaptação do currículo, introduzindo critérios de sustentabilidade.

Oferecer um curso de especialização específico sobre sustentabilidade e/ou meio ambiente.
Pesquisa, Extensão, transferência de tecnologia.
Criação de um grupo de pesquisa sobre educação, meio ambiente e sociedade.

Participação em projetos de pesquisa e de extensão sobre sustentabilidade.

Incentivo no campus para realização de pesquisa na área.

Divulgação para a sociedade dos resultados das pesquisas realizadas.
Chamadas específicas com bolsas de estudos para pesquisadores na área.

Programas de intervenção em comunidades.
Criação de um plano para construção ou remodelação de edifícios com critérios de sustentabilidade. biodiversidade.

Energia. Água.
Elaboração de plano para a gestão de áreas verdes.

Realização da sensibilização da comunidade universitária sobre a biodiversidade.
Instalação de equipamentos de energia renováveis.

Melhorias das instalações de climatização.

Desenvolvimento de um plano para o controle de consumo de energia.

Realização de melhorias no prédio para minimizar a entrada de calor, bem como instalação de luminárias de baixo consumo.

Implantação de um sistema de captação de águas pluviais para irrigação de jardins e limpeza de pisos. 


\begin{tabular}{|l|l|l|}
\hline Mobilidade. & $\begin{array}{l}\text { Ações para reduzir a necessidade de } \\
\text { deslocamento dentro do campus. } \\
\text { Realização de ações de sensibilização da } \\
\text { comunidade sobre mobilização. } \\
\text { Desencadeamento do processo de } \\
\text { elaboração da Política de Acessibilidade } \\
\text { e Inclusão. }\end{array}$ & $\begin{array}{l}\text { Convênios com empresas } \\
\text { para incentivar ao } \\
\text { transporte público. }\end{array}$ \\
$\begin{array}{l}\text { Realização de ações para } \\
\text { reduzir o impacto derivado } \\
\text { dos veículos particulares. } \\
\text { Resíduos. }\end{array}$ & $\begin{array}{l}\text { Campanhas de apoio a } \\
\text { caronas solidárias. }\end{array}$ \\
\hline $\begin{array}{l}\text { Contratação } \\
\text { Responsável. }\end{array}$ & $\begin{array}{l}\text { Criação de um plano de } \\
\text { gerenciamento de resíduos. }\end{array}$ \\
\hline $\begin{array}{l}\text { Promoção de contratação e compra } \\
\text { comércio justo e inclusão social. }\end{array}$ & $\begin{array}{l}\text { Criação de um plano de } \\
\text { redução ou compensação } \\
\text { de emissão de gases de } \\
\text { efeito estufa. } \\
\text { Criação de um protocolo } \\
\text { para introdução de critérios } \\
\text { de sustentabilidade na } \\
\text { contratação de obras, } \\
\text { serviços e abastecimento. }\end{array}$ \\
\hline
\end{tabular}

No âmbito da Política Institucional, destaca-se a aprovação do Regulamento da Política de Ambientalização e a sua inserção no item que trata dos "objetivos, metas e estratégias" na dimensão "Planejamento e Gestão Institucional" do Plano de Desenvolvimento Institucional (PDI) da UNIFEBE. Um marco a ser mencionado é a institucionalização do Comitê de Sustentabilidade, com a definição das atribuições do mesmo. Vale ressaltar que tal processo também contribuiu para que a carga horária parcial de seis horas semanais do profissional dedicado ao processo de ambientalização fosse aumentada para 16 horas, permitindo ampliação de sua atuação frente à coordenação do Comitê de Sustentabilidade e do Grupo de Pesquisa - GEMAS.

Destaca-se como desafio, nessa dimensão, a urgência na criação de um espaço físico específico para realização das atividades administrativas, de pesquisa e reuniões do Comitê de Sustentabilidade e do GEMAS que facilite, entre outras ações, o desenvolvimento de pesquisas nessa temática, a implantação de um sistema de avaliação de impacto ambiental, a captação de recursos para projetos e ações na área, e o acompanhamento de indicadores de avaliação do processo de ambientalização, seus futuros avanços e 
inovações decorrentes do trabalho pioneiro em instituições com as mesmas características político-administrativas.

No âmbito do ensino, a verificação das disciplinas que incorporam as dimensões da sustentabilidade permitirá o desenvolvimento de ferramentas e metodologias de avaliação qualitativa, assim como da incorporação da temática socioambiental nas demais. Este desafio remete a outro, talvez maior e de especial importância: a institucionalização da Assessoria de Sustentabilidade com a constituição de uma equipe que, entre outras ações, possa acompanhar as coordenações de curso no processo de adaptação do currículo, aspecto chave do processo de ambientalização curricular.

Os desafios tornam-se visíveis a partir da constatação dos avanços, que se manifestam também no ensino com a apresentação de trabalhos de conclusão de cursos de graduação que trazem como tema a sustentabilidade socioambiental. Face à importância do aprofundamento dos estudos nessa temática, especialmente pelos egressos que, ao longo do curso, demonstraram interesse por esta temática, a oferta de curso de especialização sobre sustentabilidade/ meio ambiente se apresenta como uma necessidade.

Os indicadores utilizados permitiram um olhar para além da função pedagógica da Instituição de Ensino. Aspectos como urbanismo, mobilidade, acessibilidade, inclusão e gerenciamento de água, energia e resíduos passam a ser considerados como ações integrantes do processo de ambientalização. Entre os principais avanços nestas dimensões, destaca-se o desencadeamento do processo de elaboração da Política de Acessibilidade e Inclusão, em sua face final; a melhoria nas condições e instalações estruturais dos edifícios; o monitoramento da qualidade da água e a redução dos deslocamentos no espaço do campus. 0 principal desafio é a elaboração e a implantação de planos efetivos de gestão de resíduos, água e energia.

\section{CONSIDERAÇÕES FINAIS: UM PROCESSO QUE NÃO SE CONCLUI}

O desafio de ambientalizar o ensino chega às IES em um momento oportuno, quando inúmeros trabalhos, em diferentes áreas do conhecimento, apontam para a necessidade do compromisso das IES com a sustentabilidade socioambiental. $\mathrm{O}$ trabalho em redes - inter e/ou multidisciplinares - tem se mostrado eficiente 
para o alcance de objetivos e metas comuns aos diferentes territórios, uma vez que permite, para além da aplicação e da replicação de métodos, a discussão de resultados a partir de diferentes percepções.

Considerando a ambientalização como um processo que envolve pessoas com compromisso permanente com as relações e os valores de justiça, solidariedade e equidade, acredita-se que seus resultados passam pelas relações estabelecidas entre os diferentes profissionais, a interlocução em suas ações e integração de suas práticas. Considera-se que a demonstração desta possibilidade foi evidenciada na aplicação dos Indicadores de Sustentabilidade, especialmente no processo colaborativo da elaboração da Política de Ambientalização, na sua aprovação e na institucionalização do Comitê de Sustentabilidade.

A elaboração de uma política passa pela percepção das fragilidades e das potencialidades de um determinado espaço, e, seu alcance e seu sentido estão diretamente ligados ao processo de construção. Processos participativos, dialogados, tendem a ampliar alcance e potencializar resultados. A aplicação dos mencionados indicadores na UNIFEBE evidenciou esta característica, típica do trabalho em redes, como ratificado na idealização e na realização da pesquisa da RISU em 65 IES de 10 países latino-americanos.

Sem dúvida, um dos principais avanços da aplicação dos indicadores na UNIFEBE foi a aprovação do Regimento da Política de Ambientalização, documento construído de maneira participativa, envolvendo gestores, docentes, colaboradores, acadêmicos e comunidade em geral.

Este esforço coordenado evidenciou a necessidade de superação de ações isoladas e promoveu uma maior participação da comunidade universitária com a realização de pesquisas e de atividades extracurriculares e a criação de cursos de extensão, do Grupo de Pesquisa - GEMAS, e a participação em projetos sobre ambientalização. $O$ trabalho em rede tem estimulado a instituição UNIFEBE a investir esforços na pesquisa e na extensão, tanto que se identificam demandas por pesquisas e programas de intervenção em comunidades.

O movimento observado na UNIFEBE a partir da discussão dos indicadores propostos pela RISU ampliou, inclusive, a percepção da responsabilidade socioambiental, de maneira que os investimentos na área passaram a ser registrados a fim de se garantir a memória desta frente de atuação responsável da instituição, para além da obrigatoriedade do registro imposto pela Responsabilidade Social. 
Face ao exposto, considera-se o sistema de indicadores, proposto pelo projeto da RISU, uma ferramenta imprescindível na construção de Políticas Institucionais de Ambientalização e Sustentabilidade nas IES.

Agradecimentos: Os autores expressam sinceros agradecimentos ao reitor, ao vicereitor e pró-reitor de Administração, aos pró-reitores de Ensino de Graduação e de Pós-Graduação, Pesquisa e Extensão, ao assessor jurídico e à assessora de comunicação, e aos membros do Comitê de Sustentabilidade da UNIFEBE que participaram do levantamento dos dados do projeto da RISU.

\section{REFERÊNCIAS}

BARDIN, L. Análise de conteúdo. Lisboa: Edições 70, 2008. BECK, U. Risk society. Beverly Hills: Sage, 1992.

BARRON, A.; NAVARRETE, A.; DIDAC, F. B. Sostenibilización Curricular en las Universidades Españolas. España, Rev. Eureka Enseñ. Divul. Cien., v. 7, n. Extraordinario, p. 388-399, 2010.

BENAYAS, J del A. Proyecto RISU. Definición de indicadores para la evaluación de las politicas de sustentabilidad en Universidades Latinoamericanas. Resumen Ejecutivo. Madri, Universidad Autónoma de Madri, 2014.

BRASIL. Censo da Educação Superior. Brasília: MEC/INEP, 2013. Disponível em: http://portal.inep.gov.br/web/censo-da-educacao-superior. Acesso em: 01 março 2015.

BRASIL. Ministério da Educação. Conselho Nacional de Educação - CNE. Resolução n. 2 de 15 de junho de 2012. Estabelece as Diretrizes Curriculares Nacionais para a Educação Ambiental. Brasília: MEC/CNE, 2012.

BRASIL. Programa Nacional de Educação Ambiental - ProNEA. MMA Diretoria de Educação Ambiental; Ministério da Educação. Coordenação Geral de Educação Ambiental. 3. ed. Brasília: Ministério do Meio Ambiente, 2005.

BRASIL. Lei 9.795, de 27 de abril de 1999. Dispõe sobre a educação ambiental, institui a Política Nacional de Educação Ambiental - PNEA e dá outras providências. Diário Oficial da República Federativa do Brasil, Brasília, DF, Brasília, 28 abr. 1999.

CARVAlHo, P. G. M.; BARCEllos, F. C. Políticas públicas e sustentabilidade socioambiental: Construindo indicadores de sustentabilidade. Indicadores Econômicos FEE, Porto Alegre, v. 37, n. 1, p. 1-14, 2009.

FIGUEIREDO, M. L.; GUERRA, A. F. S. UNIFEBE Sustentável: Indícios de Ambientalização em Cursos de Graduação. ANPED-SUL 10. Florianópolis, 2014. Anais.... Florianópolis: 
UDESC, 2014, p. 1-15. Disponível em: http://xanpedsul.faed.udesc.br/arq_pdf/2075-0. pdf. Acesso em: 28 fev. 2015.

GONZÁLES MUÑOZ, M. C. Principales tendências y modelos de la educación ambiental en el sistema escolar. Revista ibero-americana de educación, n. 11, p. 13-74, 1996.

GUERRA, A. F. S.; FIGUEIREDO, M. L. Ambientalização curricular na Educação Superior: desafios e perspectivas. Educar em Revista, Curitiba, Brasil, Ed. Espec. n. 3, p. 109126, 2014. DOI: 10.1590/0104-4060.38110.

GUERRA, A. F. S.; FIGUEIREDO, M. L.; RUSCHEINSKY, A. An overview of sustainability in higher education institutions in Brazil In: INTERNATIONAL CONFERENCE ON ENVIRONMENTAL EDUCATION AND SUSTAINABILITY "THE BEST OF BOTH WORLDS", 2014, Bertioga-SP. Proceedings... [recurso eletrônico]. São Paulo: University of São Paulo, Social Service of the Commerce, 2014. v.e-book. p. $346-352$

GUERRA, A. F. S.; FIGUEIREDO, M. L.; SAENZ, O. (Coords.) II Jornada Ibero-americana da ARIUSA. Itajaí: Livro eletrônico, Univali, 2012.

JUNYENT, M.; GELI, A. M.; ARBAT, E. Características de la ambientalización curricular: Modelo ACES. In: JUNYENT, M., GELI, A. M., ARBAT, E. (Eds.) Ambientalización Curricular de los Estudios Superiores. Proceso de Caracterización de la Ambientalización Curricular de los Estudios Superiores. Girona: Universitat de Girona, Red ACES, 2003. v. 2, p. 15- 32.

KITZMANN, D. Ambientalização de Espaços Educativos: aproximações metodológicas. Rev. Eletrônica Mestr. Educ. Ambient., v. 18, p. 553-574, 2007.

KITZMANN, D; ASMUS, M. L. Ambientalização sistêmica - do currículo ao socioambiente. Currículo sem Fronteiras, v. 12, n. 1, p. 269-290, jan./abr. 2012.

LEME, P. C. S.; PAVESI, A.; ALBA, D.; DIAZ GONZÁLEZ, M. J. (Org.) Visões e experiências Ibero-Americanas de Sustentabilidade nas Universidades: desdobramentos do $3^{\circ}$ Seminário Internacional de Sustentabilidade na Universidade. São Carlos, SP, Brasil; Madrid: UAM, 2012.

LEFF, E. Saber ambiental: sustentabilidade, racionalidade, complexidade, poder. 3. ed. Petrópolis, RJ: Vozes, 2004.

OLIVEIRA, H.T.; FREITAS, D. O contexto político-pedagógico e a construção de características para diagnosticar e implementar a ambientalização curricular nos cursos de graduação na Universidade Federal de São Carlos. In: M. JUNYENT; A. M. GELI; E. ARBAT. (Org.). Ambientalización Curricular de los Estudios Superiores. 2 -Proceso de Caracterización de la Ambientalización Curricular de los Estudios Superiores. Girona: Editora UdG, 2003, v.40, p.125-137.

RUSCHEINSKY, A.; GUERRA, A. F. S.; FIGUEIREDO, M. L.; LEME, P. C. S; RANIERI, V. E. L.; DELITTI, W. B. C. Ambientalização nas instituições de educação superior no Brasil: 
caminhos trilhados, desafios e possibilidades. São Carlos-SP: EESC/USP, 2014.

SANTANA, L. C.; CAVALARI, R. M. F.; CARVALHO, L. M. A ambientalização curricular na UNESP - Campus de Rio Claro: Análise de uma proposta de intervenção prática. In: GELI, A. M.; JUNYENT, M.; SÁNCHEZ, S. (Eds.) Ambientalización curricular de los estudios superiores 4- Acciones de Intervención para la Ambientalización Curricular de los Estudios Superiores. Girona: Universitat de Girona - Red ACES, 2003, p. 131-153.

Artigo recebido em março de 2015 Aprovado em abril de 2015 